\title{
Dampak Cognitive Moral Development Terhadap Kejujuran \\ Pelaporan Anggaran
}

\author{
Tommy Wijaya \\ Universitas Katolik Soegijapranata \\ tomywijaya229@gmail.com
}

\begin{abstract}
This study aims to analyze the impact of Cognitive Moral Development in honesty budget reporting because honesty in employees is important in the success of a company so it needs to be formed early. The development of Cognitive Morals is justification in making decisions relating to social actions to act ethically. Honesty of budget reporting in this study has a treatment in order to give an ethical dilemma effect on participants in decision making. The sample of this study was 48 active students of Soegijapranata Catholic University Semarang who have taken Cost Accounting courses. This study uses DIT (Define issue test) on cognitive moral development and SPSS programs. The results showed that individuals with high levels of cognitive moral development tend to be more honest in reporting budgets so that it can be said that cognitive moral development affects the honesty of budget reporting. Under optimal hurdle contract, individuals tend to be more honest in reporting budgets than in contract trust conditions so it can be said that there are differences in cognitive moral development in honesty of budget reporting.
\end{abstract}

Key words: cognitive moral development, honesty of budget reporting

\begin{abstract}
Abstrak
Penelitian ini bertujuan untuk menganalisis dampak Cognitive Moral Development dalam kejujuran pelaporan anggaran karena kejujuran pada karyawan merupakan hal yang penting dalam keberhasilan suatu perusahaan sehingga perlu dibentuk sejak dini. Cognitive Moral Development merupakan dasar pembenaran dalam pengambilan keputusan yang berkaitan dengan tindakan sosial untuk bertindak etis. Kejujuran pelaporan anggaran dalam penelitian ini memiliki treatment untuk memberikan efek dilema etis pada partisipan dalam pengambilan keputusan. Sampel penelitian ini adalah 48 mahasiswa aktif Universitas Katolik Soegijapranata Semarang yang telah mengambil mata kuliah Akuntansi Biaya. Penelitian ini menggunakan DIT (Define issue test) untuk cognitive moral development dan program SPSS. Hasil penelitian menunjukan bahwa individu dengan tingkat cognitive moral development yang tinggi cenderung lebih jujur dalam melaporakan anggaran sehingga dapat dikatakan bahwa cognitive moral development berpengaruh terhdap kejujuran pelaporan anggaran. Pada kondisi optimal hurdle contract individu cenderung lebih jujur melaporkan anggaran dibandingkan pada kondisi trust contract sehingga dapat dikatakan bahwa terdapat perbedaan dalam cognitive moral development terhadap kejujuran pelaporan anggaran.
\end{abstract}

Kata kunci: cognitive moral development, hurdle contract, trust contract kejujuran pelaporan anggaran 


\section{PENDAHULUAN}

Dalam sebuah organisasi, setiap pekerja yang ada didalamnya memiliki tujuan agar dapat memajukan perusahaan yang telah diotorisasikan oleh para investor kepada organisasi tersebut untuk menghasilkan laba seoptimal mungkin. Secara formal anggaran merupakan alat ukur untuk penilaian kinerja organisasi dalam menjalankan perusahaan. Manajemen perusahaan berupaya semaksimal mungkin dalam penyusunanan, perencanaan, pengendalian pelaksanaan anggaran agar dapat tercapai sampai periode tersebut berakhir.

Dalam penyusunan anggaran sampai merealisasikannya jika sudah terjadi penyimpangan informasi oleh manajemen maka dapat dipastikan terdapat kecurangan yang telah dilakukan oleh manajemen. Faktor generik yang berhubungan dengan organisasi yang melakukan kecurangan dikarenakan adanya pengaruh asimetri informasi. Walaupun tidak menutup kemungkinan penyimpangan informasi tersebut juga untuk menjaga nama baik akuntan manajer sehingga dia mengambil keputusan yang tidak etis dan memberikan informasi perusahaan secara tidak jujur kepada para pemangku kepentingan.

Dalam dunia bisnis kecurangan yang dilakukan akuntan telah menjadi perhatian publik dan pelaku bisnis karena menimbulkan kerugian yang besar (Adelin, 2013). Dalam penelitian Chung dan Hsu (2017) mengatakan kecurangan yang dilakukan seperti misreporting merupakan sebuah penipuan atau kejahatan ekononomi dalam dunia bisnis, dan skandal bisnis yang disebabkan oleh perilaku manajer yang tidak etis.

Oleh karena itu, manajer pun dalam pembuatan, pengendalian pelaksaan anggaran diperlukannya kejujuran dan kewajaran untuk mengungkapkan keadaan yang sesungguhnya diterjadi dalam perusahaan (Chung dan Hsu, 2017). Hal tersebut dapat menimbulkan pola pikir yang buruk dikalngan para pelaku bisnis dan publik tentang manajer akuntan karena perilaku tidak etis yang dilakukan dalam pelaporan anggaran.

Chung dan Hsu (2017) dalam penelitiannya yang membahas pengaruh cognitive moral development (CMD) terhadap kejujuran pelaporan anggaran untuk mengetahui apakah CMD berpengaruh pada kejujuran pelaporan anggaran. Karena CMD merupakan dasar dari perilaku etis dalam pengambilan keputusan seperti perencanaan anggaran yang dilakukan oleh manajemen akuntan. Penelitian tersebut menunjukkan hubungan positif antara cognitive moral development dengan kejujuran pelaporan anggaran. Dengan kata lain, semakin tinggi tingkat CMD seseorang maka semakin jujur dalam melaporkan pelaporan anggaran.

Dalam penelitian Chung dan Hsu (2017) skenario anggaran mengunakan imbalan yang diterima peserta dengan adanya trust Contract dan optimal hurdle contract. Pengaturan optimal hurdrle contract memberikan batasan harga komponen biaya dalam penyusunan anggaran yang hendak diajukan ke kantor pusat untuk mendapat persetujuan. Sementara untuk trust contract tidak ada batas harga komponen biaya yang diajukan kepada kantor pusat. Kondisi ini membuat dilema pada peserta saat menyusun anggaran.

Penelitian ini mereplikasi penelitian sebelumnya dengan menganti sample pada penelitian. Replikasi ini bertujuan untuk memperkuat validitas eksternal penelitian terdahulu. Penelitian ini mencoba mencari tahu apakah terdapat perbedaan kejujuran pelaporan anggaran pada tingkat cognitive moral development dengan menggunakan sampel mahasiswa Universitas Katolik Soegijapranata. Namun imbalan yang diterima dalam penelitian sebelumnya diganti dengan saving bond ritel (SBR) yang diterbitkan mentri keuangan Indonesia sebagai pendanaan APBN Indonesia dimana SBR tersebut dijamin oleh undangundang.

Anggaran yang dibuat oleh manajer tersebut dikelompokan menjadi 2 model yaitu model trust contract dan optimal hurdle contract sama dengan penelitian sebelumnya. Sampel diambil dari 2 kelas, kelas 1 mengunkan anggaran model trust contract tanpa ada batas penyusunan anggaran dan kelas ke 2 mengunakan optimal hurdle contract yang 
memiliki batas penyusunan untuk pendanaan anggaran. Syarat kelas yang diambil sebagai sampel adalah mahasiswa telah mengambil mata kuliah Akuntansi Manajemen. Pengambilan sampel pada penelitian ini dilakukan 2 sesi yaitu sesi 1 peserta dijelaskan serta dibacakan mengenai kasus kemudian disuruh mengisi kuesioner Cognitive moral development. Kemudian pada sesi ke dua peserta diberikan lembar spreadsheet untuk pengisian anggaran yang sebelumnya dijelaskan aturannya oleh peneliti.

Karena banyaknya kasus penipuan, kecurangan, penyimpangan informasi oleh para akuntan yang menyebabkan terjadinya krisis kepercayaan pada profesi akuntan oleh para pembisnis, investor, dan publik. Perilaku tidak etis yang dilakukan akuntan tersebut didasari oleh Cognitive Moral Development pribadi dalam pengambilan keputusan. Sehingga diperlukannya penelitian untuk menguji tingkat Cognitive Moral Development pada kejujuran pelaporan anggaran yang dibuat oleh manajer akuntan agar dapat diperbaiki etika para calon akuntan dan akuntan manajer. Supaya para universitas dapat mendidik serta menghasilkan kualitas akuntan yang handal dan dapat merubah pola piker publik tentang akuntan.

\section{TINJAUAN LITERATUR DAN PERUMUSAN HIPOTESIS}

\section{Cognitive Moral Development}

Teori Cognitive Moral Development sering kali digunakan untuk menjelaskan dasar tindakan yang dilakukan oleh individu seperti dalam pengambilan sebuah keputusan dan sebuah tindakan. Teori ini dibangun berdasarkan pertimbangan moral dalam pembenaran pengambilan satu keputusan atau nilai yang berkaitan dengan tindakan sosial (Rest et al., 1999). Ada tiga level perkembangan moral yaitu : Pre-conventional, conventional dan Post conventional.

Level 1: Pre-conventional. Dalam tahap ini, individu masih dalam keadaan primitif. Individividu hanya berfikir untuk dirinya sendiri dan tidak menghiraukan kepentingan individu lainnya. Setiap individu ingin dianggap benar.

Level 2: Conventional. Dalam tahap ini, individu telah memiliki persepsi tentang keberadaan, harapan-harapan keluarga, kelompok, dan negara. Individu juga memiliki ekspetasi interpersonal, memiliki orientasi keserasian hubungan antar individu, dan memiliki dorongan untuk berperilaku patuh kepada peraturan yang berlaku.

Level 3 Post-Conventional. Dalam tahap ini, individu memiliki otonomi dan menjadi pribadi yang berprinsip. Individu memiliki kesadaran bahwa nilai-nilai dan pendapat personal bersifat relatif. Setiap keputusan diberikan penekanan pada aturan/hukum. Individu memiliki prinsip -prinsip yang bersifat abstrak dan etis dan meresap di dalam hati sebagai prinsip keadilan, prinsip timbal balik, dan prinsip persamaan hak-hak manusia serta menempatkan manusia sebagai individu personal yang bermartabat.

Cognitive Moral Development yang sering juga disebut sebagai kesadaran moral (moral reasoning, moral judgment, moral thingking) merupakan faktor yang penting dalam pengambilan keputusan etis. Perilaku moral yang sebenarnya dapat ditelusuri melalui penalarannya (Palupi dan Mulyanto, 2014). Dalam menjalankan tugas, akuntan manajer selalu dihadapkan dengan pilihan-pilihan etis pada saat pengambilan keputusan. Oleh karena itu perusahaan perlu mempertimbangkan penempatan akuntan manajer berdasarkan tingkat moral yang dimiliki agar dapat menghindari kecurangan yang mungkin terjadi.

\section{Kejujuran pelaporan anggaran}

Anggaran yang dibuat oleh manajer berisikan informasi mengenai perencanaan perusahaan untuk kedepannya. Anggaran adalah rencana yang disusun secara sistematis, yang meliputi seluruh kegiatan, yang dinyatakan dalam unit (satuan) moneter dan berlaku untuk jangka panjang (periode) tertentu yang akan datang (Sutrisni, 2014). Anggaran digunakan 
untuk memotivasi, merencanakan, mengkoordinasi, dan pengendali setiap elemen dalam perusahaan seperti pemasaran, operasi dan sumber daya.

Dalam perusahaan yang terdesentralisasi, manajer menyiapkan anggaran dan laporan keuangan dan mengomunikasikan informasi lokal yang berharga kepada atasan mereka untuk membantu dalam operasi pemasaran, dan keputusan investasi. Manajer diharuskan untuk mengungkapkan semua informasi yang relevan kepada pemberi kerja, karena menyembunyikan informasi yang relevan dari perusahaan adalah tidak etis. Sehingga untuk menghasilkan sebuah informasi yang relevan akuntan manajer harus menyajikan secara transparan tanpa menutupi sesuatu, karena informasi yang dihasilkan tersebut dipergunakan untuk mengambilan keputusan oleh atasan (Chung dan Hsu, 2017).

Seorang individu dengan penalaran moral yang baik ketika dihadapkan dengan sebuah peluang untuk melakukan kecurangan agar dapat memperkaya dirinya sendiri atau kelompoknya, akan membuat penalaran moralnya menjadi dilemma. Oleh karena itu, penalaran moral individu akan menjadi dilemma pada saat memiliki peluang dalam mengambil keputusan untuk melakukan kecurangan agar dapat bertindak secara etis maupun tidak etis dalam menyikapi peluang kecurangan. Sehingga hal tersebut akan mempengaruhi kejujuran individu untuk berbuat etis dan tidak etis dalam mengambilan keputusan, terkait peluang kecurangan untuk memperkaya diri sendiri dan kelompoknya dari pelaporan anggaran. Karena, kejujuran pelaporan merupakan preferensi kejujuran dalam mendahulukan kepentingan atau kepentingan lainya. Maka, hal tersebut akan menjadi dilemma pada presepsi moral individu dalam menyikapi peluang kecurangan untuk bertindak jujur atau tidak dalam melaporakan anggaran.

Chung dan Hsu (2017) menyimpulkan bahwa terdapat hubungan positif cognitive moral development individu dengan kejujuran pelaporan anggaran. dimana individu dengan cognitive moral development yang baik cenderung lebih jujur dalam penyerahkan pelaporan anggaran. Oleh karena itu, seseorang yang memiliki penalaran moral yang baik akan membuat orang tersebut lebih mempertimbangkan keputusan untuk melakukan tindakan yang etis dalam menyikapi adanya peluang kecurangan saat penyusunan pelaporan anggaran. Sehingga hipotessis pertama dalam penelitian ini yaitu:

\section{H1: Cognitive Moral Development berpengaruh terhadap kejujuran pelaporan anggaran}

Individu dengan cognitive moral developemt yang tinggi akan bertindak dengan benar dalam pengambilan keputusan terkait penalaran moralnya. Walaupun terdapat perluang untuk melakukan kecurangan yang memiliki tingkat tekanan moral dalam pengambilan keputusan. Karena cognitive moral development merupakan bentuk penalaran moral dalam melakukan tindakan yang berhubungan dengan moral sosial (Palupi dan ulyanto, 2014). Sehingga, setiap keputusan yang hendak diambil individu dengan adanya tekanan moral akan membuat penalaran moral individu menjadi dilemma dalam pengambilan keputusan untuk bertindak jujur atau tidak dalam menyikapi peluang kecurangan penyusunan anggaran.

Dalam penyusunan anggaran (Evans et al., 2001) menyarankan untuk menambah tekanan moral yang membuat dilemma partisipan maka diberikan dua kondisi pengaturan. Dua kondisi yang diusulkan yaitu kondisi trust contract dan optimal hurdle contract, dimana trust contract merupakan kondisi yang memberikan kebebasan pada partisipan pada pembebanan biaya anggaran dan optimal hurdle contract merupakan kondisi dimana pembebanan biaya pada anggaran akan mendapat persetujuan jika biaya tersebut tidak melebihi batas yang telah ditentukan perusahaan.

Oleh karena itu, individu dengan kemampuan penalaranan moral yang tinggi akan menjadi semakin dilemma dalam pengambilan keputusan melakukan kecurangan jika dihadapkan dengan dua kondisi tekanan moral yang berbeda. 
Chung dan Hsu (2017) menunjukan bahwa seorang dengan tingkat cognitive moral development yang tinggi menghasilkan laba yang lebih tinggi pada trust contract dari pada optimal hurdle contract. Seseorang dengan cognitive moral development yang tinggi dapat melakukan kecurangan untuk memperkaya diri sendiri maupun kelompok. Walaupun penalaran moral individu dihadapkan pada kondisi tekanan moral yang berbeda dengan tingkat keleluasaan yang berbeda, pada saat menyusun anggaran perusahaan untuk pelaporan anggaran secara jujur dan tidak jujur. sehingga hipotesis penelitian ini yaitu:

\section{H2a: Terdapat perbedaan kejujuran pelaporan anggaran antara cognitive moral development yang tinggi pada kondisi trust contract dan optimal hurdle contract}

Individu dengan tingkat cognitive moral development yang rendah cenderung lebih mementingkan keuntungan pribadi dan berupaya agar dapat melakukan berbagai cara untuk dapat memperkaya dirinya sendiri dengan melakukan kecurangan. Karena itu, individu dengan cognitive moral development yang rendah memiliki petimbangan yang kurang tepat dalam pengambilan keputusan terkait penalaran moral mereka dalam pengambilan keputusan untuk melakukan kecurangan dalam pengambilan keputusan untuk melaporkan anggaran secar jujur agar dapat memperkaya diri sendiri dan kelompoknya.Peluang kecurangan yang ada dengan tingkat tekanan moral yang berbeda, dapat membuat dilemma pada penalaran moral individu dalam mengungkapkan pelaporan anggaran secara jujur tanpa mengutamakan kepentingan dirinya.

Chung dan Hsu (2017) memberi bukti bahwa manajer akuntan dengan cognitive moral development yang rendah menunjukan hasil laba yang tinggi pada kondisi optimal hurdle contract dibandingkan kondsi trust contract. Oleh karena itu, seseorang dengan cognitive moral development yang rendah harus diberikan tekanan moral agar jujur dalam pengungkapan pelaporan anggaran untuk menghindari kecurangan.

Berdasarkan argumen di atas, hipotesis berikut ini dapat dirumuskan:

H2b: terdapat perbedaan kejujuran pelaporan anggaran pada tingkat cognitive moral development yang rendah pada kondisi trust contract dan optimal hurdle contract.

\section{METODA PENELITIAN}

\section{Populasi dan sampel}

Partisipan pada penelitian ini adalah mahasiswa aktif Fakultas Ekonomi dan Bisnis Unika Soegijapranata Program Studi Akuntansi tahun ajaran 2017/2018 yang telah mengambil mata kuliah Akuntansi Manajemen yang dikondisikan sebagai manajer akuntan dalam suatu perusahaan. Desain eksperimen dalam penelitian ini adalah $2 \times 2$ (tingkat cognitive moral development $\mathrm{x}$ kejujuran pelaporan anggaran). Hartono, (2013) untuk jumlah subjek sampel yang digunakan sebanyak 10 orang tiap sel. Namun dalam penelitian ini akan mengambil lebih dari 10 orang tiap sel, agar dapat mengantisipasi jika ada subjek sampel yang tidak lolos uji manipulasi

\section{Pengukuran variabel}

\section{Cognitive Moral Development}

Cognitive moral development merupakan variabel independen yang mempengaruhi kejujuran pelaporan anggaran partisipan, variabel ini memiliki arti makna persepsi tingkat penalaran moral sebagai argumentasi untuk membuat keputusan yang memiliki nilai moral, dimana partisipan merasakan bahwa kejujuran dalam pelaporan anggaran akan memberikan pengaruh pada laba perusahaan. Variabel cognitive moral development dalam penelitian ini memiliki dua kondisi yaitu tinggi dan rendah. Cognitive Moral Development tinggi yaitu 
enalaran moral yang tinggi dirasakan akan mempengaruhi kejujuran dalam pelaporan anggaran yang dapat membuat pengaruh pada laba yang dihasilkan oleh perusahaan. sedangkan Cognitive Moral Development rendah yaitu penalaran moral yang rendah dirasakan akan mempengaruhi kejujuran dalam pelaporan anggaran yang dapat membuat pengaruh mengenai turunnya laba yang dihasilkan oleh perusahaan.

Pengukuran cognitive moral development pada eksperimen penelitian ini diukur dengan define issue test (DIT) yang dikembangkan Rest et al. (1997) dalam (Mcmahon, 2000) mengunakan untuk mengukur pertimbangan etika level post-convensional (level 3), tingkat 5 dan 6. Instrumen ini merangking preferensi pengembangan moral individu dengan Principled score (P-score) untuk mengidentifikasi alternatif respon pernyataan pada setiap item kasus untuk dipertimbangkan dalam pembuat keputusan etika. P-score memuat kepentigna relative yang diberikan pada pertimbangan prinsip moral dan pengambilan keputusan tentang dilemma. Cognitive moral development tinggi jika nilai score subjek $>$ nilai median total keseluruhan. Cognitive moral development rendah jika nilai score subjek < nilai median total keseluruhan.

Penentuan tinggi atau rendah tingkat penalaran moral seserang ditentukan dari median dari P-score seluruh partisipan. Pengukuran variabel cognitive moral development dengan mengunakan skala rasio.

\section{Kejujuran pelaporan anggaran}

Kejujuran pelaparan anggaran merupakan variabel dependen yang dipengaruhi oleh cognitive moral development partisipan, merupakan preferensi kejujuran dalam mendahulukan kepentingan diri sendiri atau yang lain (Rosdini, n.d.). Pengukuran kejujuran pelaporan anggaran dari penelitian ini diukur dengan rumus

$$
\pi=1-\frac{\text { Budget Cost }- \text { Actual Cost }}{6000-\text { Actual Cost }} \times 100 \%
$$

Semakin banyak biaya yang dibebankan pada anggaran oleh partisipan maka membuat mereka semakin tidak jujur dalam melaporakan anggaran. Sebaliknya, apabila biaya yang dibebankan sesuai dengan biaya aktual maka menunjukan bahwa partisipan tersebut jujur. Varibel kejujuran pelaporan diukur dengan skala ordinal $0=$ tidak jujur dan $1=$ jujur. Namun, dalam penelitian eksperimen ini memiliki 2 kondisi pengaturan yaitu sebagai berikut.

a. Trust contract. Dalam penyusunan anggaran diberikan kebebasan dalam pembebanan anggaran karena terdapat penurunan harga. Akan tetapi range harga yang di berikan antara Rp 4.000 sampai $\mathrm{Rp} 6.000$.

b. Optimal hurdle contract. Dalam penyusunan anggaran terdapat penurunan harga dengan range Rp 4.000 sampai Rp 6.000 namun, hanya disetujui jika pembeban biaya tersebut kurang dari $\mathrm{Rp} 5.500$

\section{HASIL DAN PEMBAHASAN}

Tabel 1 menggambarkan jumlah keseluruhan dari partisipan pada eksperimen ini adalah 53 partisipan yang diambil dari 2 kelas yaitu kelas praktikum audit kelas 01 (kondisi optimal hurdle contract) dan akuntansi perbankan kelas 01 (kondisi trust contract). Dalam menjalankan eksperimennya peneliti terlebih dahulu melakukan uji manipulasi agar subjek paham mengenai pengisian kuesioner cognitive moral development maupun kejujuran pelaporan anggaran mengenai pembebanan biaya bahan baku. Setelah melakukan eksperimen peneliti mendapatkan 48 partisipan yang lolos uji manipulasi dan terdapat 5 partisipan yang tidak lolos uji manipulasi karena pada kuesioner cognitive moral development pada bagian ranking partisipan menjawab tidak sesuai dengan yang dijelaskan oleh peneliti. Partisipan ada yang memberikan jawaban silang pada tabel ranking, ada yang memberikan ranking tiap 
tabel diberikan nomer berjumlah 4, 3, 2 sehingga partisipan tersebut dinyatakan bahwa tidak lolos uji manipulasi.

Tabel 1. Jumlah Partisipan Yang Mengikuti Eksperimen

\begin{tabular}{|c|r|r|r|r|}
\hline $\begin{array}{c}\text { Kejujuran pelaporan } \\
\text { anggaran }\end{array}$ & $\begin{array}{l}\text { subje } \\
\mathbf{k} \\
\mathbf{m i n i} \\
\mathbf{m u m}\end{array}$ & $\begin{array}{c}\text { Partisip } \\
\text { an yang } \\
\text { mengiku } \\
\text { ti } \\
\text { eksperi } \\
\text { men }\end{array}$ & $\begin{array}{c}\text { Partisipan } \\
\text { yang } \\
\text { tidak lolos } \\
\text { uji } \\
\text { manipulas } \\
\mathbf{i}\end{array}$ & $\begin{array}{c}\text { Partisipan } \\
\text { yang lolos uji } \\
\text { manipulasi }\end{array}$ \\
\hline Kondisi Trust contract & 20 & 27 & 2 & 25 \\
\hline kondisi Optimal hurdle & 20 & 26 & 3 & 48 \\
contract & & 53 & 5 & 23 \\
\hline
\end{tabular}

Sumber: Data primer diolah, 2019

\section{Deskriptif statistik}

Statisik desktiptif adalah sebuah informasi yang diolah dan digunakan untuk membantu memberikan penjelasan terkait variabel dalam penelitian ini. Varibel cognitive moral development (independen) diukur dengan nilai median yang diambil dari skor seluruh partisipan masing- masing kondisi sebagai pemisah antara tingkat cognitive moral development yang rendah dan tinggi. Pada penelitian ini variabel dependen adalah kejujuran pelaporan anggaran yang diukur dengan rumus:

$$
\pi=1 \text {-(Budget Cost-Actual Cost) / (6000-Actual Cost) } \times 100 \%
$$

Apabila hasil dari perhitungan semakin mendekati 1 maka semakin jujur partisipan dalam membebankan biaya pada pelaporan anggaran.

Tabel 2. Nilai Median cognitive moral development.

\begin{tabular}{|c|c|}
\hline Keterangan & Nilai Median \\
\hline CMD kondisi Trust Contract & 14 \\
\hline CMD kondisi Optimal Hurdle Contract & 13 \\
\hline
\end{tabular}

Sumber: Data Primer, diolah 2019

Tabel 2 menyajikan nilai median pada cognitive moral development yang bertujuan sebagai pemisah antara CMD yang rendah dan CMD yang tinggi, dimana jika nilai total CMD partisipan kurang dari < 14 maka dapat dikatakan bahwa partisipan memiliki tingkat CMD yang rendah dan jika nilai total CMD partisipan sama atau lebih besar dari $\geq 14$ maka dapat dikatakan bahwa partisipan memilik tingkat CMD yang tinggi.

Tabel 3 menampilkan statistik deskriptif pada tingkat cognitive moral development pada kondisi trust contract dan optimal hurdle contract pada partisipan.

Tabel 3. Rata-rata cognitive dan kejujuran berdasarkan jenis kelamin

\begin{tabular}{|c|c|r|r|r|r|r|r|}
\hline \multirow{2}{*}{} & \multicolumn{3}{|c|}{ Trust Contract } & \multicolumn{2}{c|}{ Optimal Hudle Contract } \\
\cline { 3 - 8 } \multicolumn{2}{|c|}{} & $\begin{array}{c}\text { J } \\
\text { ml }\end{array}$ & $\begin{array}{c}\text { CM } \\
\text { D }\end{array}$ & $\begin{array}{c}\text { Kejujur } \\
\text { an }\end{array}$ & $\begin{array}{c}\text { J } \\
\text { ml }\end{array}$ & $\begin{array}{c}\text { CM } \\
\text { D }\end{array}$ & $\begin{array}{c}\text { Kejujur } \\
\text { an }\end{array}$ \\
\hline \multirow{2}{*}{$\begin{array}{c}\text { Cogniti } \\
\text { ve } \\
\text { Tinggi }\end{array}$} & Laki-laki & $\mathbf{2}$ & $\mathbf{1 5 , 5}$ & $\mathbf{0 , 5 0}$ & $\mathbf{6}$ & $\mathbf{1 6 , 1}$ & $\mathbf{0 , 6 1}$ \\
\cline { 2 - 8 } & $\begin{array}{c}\text { Perempu } \\
\text { an }\end{array}$ & $\mathbf{1 3}$ & $\mathbf{1 6 , 1}$ & $\mathbf{0 , 6 6}$ & $\mathbf{6}$ & $\mathbf{1 5 , 1}$ & $\mathbf{0 , 6 4}$ \\
\hline $\begin{array}{c}\text { Cogniti } \\
\text { ve } \\
\text { Rendah }\end{array}$ & Laki-laki & $\mathbf{1}$ & $\mathbf{1 0}$ & $\mathbf{0}$ & $\mathbf{5}$ & $\mathbf{1 0 , 8}$ & $\mathbf{0 , 5 3}$ \\
\cline { 2 - 8 } & $\begin{array}{c}\text { Perempu } \\
\text { an }\end{array}$ & $\mathbf{9}$ & $\mathbf{1 1 , 6}$ & $\mathbf{0 , 7 6}$ & $\mathbf{6}$ & $\mathbf{9 , 1}$ & $\mathbf{0 , 6 1}$ \\
\hline
\end{tabular}

Sumber: Data primer, diolah 2019 
Dari tabel dapat diketahui bahwa kondisi trust contract, laki-laki dengan tingkat CMD yang rendah dan CMD yang tinggi memiliki CMD yang lebih kecil dibandingkan perempuan. Pada kondisi optimal hurlde contract, laki laki dengan tingkat CMD yang rendah dan CMD yang tinggi justru memiliki tingkat CMD yang lebih besar dibandingkan perempuan. Pada tabel 3 juga dapat dilihat bahwa perempuan dengan tingkat CMD yang tinggi pada kondisi trust contract maupun optimal hurlde contract cenderung lebih jujur dalam melaporakan anggaran. pada tingkat CMD yang rendah pun perempuan lebih jujur dalam melaporakan anggaran dibandingkan laki-laki.

\section{Uji Hipotesis}

\section{Hasil Pengujian Hipotesis 1}

Sebelum memaparkan hasil pengujian hipotesis, Tabel 4 menampilkan desain eksperimen pada penelitian ini yang memiliki 2 tingkat cognitive moral development yang berbeda dengan kondisi trust contract dan optimal hurdle contract pada kejujuran pelaporan anggaran.

Tabel 4. Desain Eksperimen

\begin{tabular}{|c|r|r|r|}
\hline \multicolumn{2}{|c|}{} & \multicolumn{3}{|c|}{ Kejujuran pelaporan anggaran } \\
\hline \multirow{2}{*}{$\begin{array}{c}\text { Cognitive moral } \\
\text { development }\end{array}$} & Tinggi & 1 & 2 \\
\cline { 2 - 4 } & Rendah & 3 & 4 \\
\hline
\end{tabular}

Sumber: Data primer diolah, 2019

Pengujian hipotesis 1 dilakukan untuk mengetahui apakah terdapat pengaruh cognitive moral development terhadap kejujuran pelaporan anggaran. Hasil pengujian dapat dilihat pada Tabel 5 di bawah ini.

Tabel 5. Hasil Pengujian Hipotesis 1.

\begin{tabular}{|c|r|r|r|}
\hline & \multicolumn{2}{|c|}{ Mean } & Sig. \\
\hline CMD & 480.00 & 70.00 & 0.000 \\
Tinggi & & & \\
\hline CMD & 507.69 & 136.36 & \\
Rendah & & & \\
\hline
\end{tabular}

Sumber: Data Primer diolah, 2019 (lampiran II)

Dari Tabel 5 terlihat bahwa nilai rata-rata tingkat cognitive moral development yang tinggi adalah 480.00 dan 70.00 dan yang rendah adalah 507.69 dan 136.36 sehingga dapat dikatakan bahwa tiap kelas pada tingkat cognitive moral development yang tinggi dan rendah memiliki perbedaan yang signifikansi. Perbedaan signitifikan pada cognitive moral development terhadap kejujuran pelaporan anggaran secara statistik memiliki nilai signifikansi .000 dengan demikian dapat dikatakan bahwa cognitive moral development tersebut memiliki pengaruh yang signifikan pada kejujuran pelaporan anggaran karena nilai signifikansi ( $p$-value) kurang dari 0,05. Dengan demikian Hipotesis satu diterima.

Tabel diatas juga menunjukan adanya perbedaan rata-rata kejujuran pelaporan anggaran pada kondisi trust contract dan optimal hurdle contract dengan tingkat cognitive moral development yang rendah maupun yang tnggi. Jadi, terdapat perbedaan antara tingkat cognitive moral development dalam kondisi trust contract dan optimal hurdle contract sehingga hal ini sejalan dengan penelitian (Puspasari, 2012) yang mengatakan bahwa 
penalaran moral berpengaruh secara signifikan pada pengendalian internal yang membuat individu dengan level penalaran tertentu untuk melakukan kecurangan akuntansi.

\section{Hasil Pengujian Hipotesis 2a}

Pengujian hipotesis 2a digunakan untuk mengetahui apakah terdapat perbedaan kejujuran pelaporan anggaran dengan kondisi trust contract dan optimal hurdle contract pada tingkat cognitive moral development yang rendah

Tabel 6. Desain Hipotesis 2a.

\begin{tabular}{|c|c|r|r|}
\hline \multirow{2}{*}{} & \multicolumn{2}{|c|}{ Kejujuran pelaporan anggaran } \\
\cline { 3 - 4 } & Trust contract & $\begin{array}{c}\text { Optimal hurdle } \\
\text { contract }\end{array}$ \\
\hline \multirow{2}{*}{$\begin{array}{c}\text { Cognitive moral } \\
\text { development }\end{array}$} & Rendah & 1 & 2 \\
\cline { 2 - 4 } & Tinggi & 3 & 4 \\
\hline
\end{tabular}

Sumber: Data primer diolah, 2019

Tabel 6 diatas menampilkan desain eksperimen untuk menguji hipotesis 2a yang dilakukan dengan independent sample t test. Uji beda dilakukan pada kejujuran pelaporan anggaran kondisi trust contract dan optimal hurdle contract dengan tingkat cognitive moral development yang rendah. Berhubung penelitian ini menggunakan independent sample t test, maka uji normalitas dilakukan terlebih dahulu untuk memastikan bahwa sampel pada penelitian ini terdistribusi normal dengan menggunakan pengujian Kolmogorov-Smirnov.

\section{Tabel 7. Hasil Kolmogorov Smirnov Hipotesis 2a.}

\begin{tabular}{|c|c|c|c|c|}
\hline $\begin{array}{c}\text { Kejujuran } \\
\text { pelaporan } \\
\text { anggaran dengan }\end{array}$ & & $\begin{array}{l}\text { Asymp. } \\
\text { Sig (2- } \\
\text { tailed) }\end{array}$ & Mean & Sig. \\
\hline $\begin{array}{c}\text { tingkat Cognitive } \\
\text { Moral }\end{array}$ & $\begin{array}{c}\text { Kelas Trust } \\
\text { contract }\end{array}$ & \multirow[t]{2}{*}{0,174} & 480.00 & \multirow[t]{2}{*}{0.024} \\
\hline $\begin{array}{l}\text { Development } \\
\text { rendah }\end{array}$ & $\begin{array}{l}\text { Kelas Optimal } \\
\text { hurdle contract }\end{array}$ & & 136.36 & \\
\hline
\end{tabular}

Sumber: Data Primer diolah, 2019.

Tabel 7 diatas menunjukkan bahwa signifikansi sebesar 0,174 untuk kondisi cognitive moral development yang rendah pada kelas trust contract dan optimal hurdle contract. Dengan demikian hasil data terdistribusi normal dan dapat melakukan uji independen sampel t test karena signifikansi $>0.05$. Tabel diatas juga menunjukkan nilai sig 0.024 , karena nilai sig $<0.05$ maka dapat dikatakan bahwa adanya perbedaan kejujuran pelaporan anggaran kelas trust contract dan optimal hurdle contract pada tingkat cognitive moral development yang rendah. Tabel diatas juga menunjukan bahwa individu dengan tingkat penalaran moral yang rendah pada kondisi trust contract memiliki rata-rata ketidak jujuran yang lebih tinggi karena membebankan biaya bahan baku lebih besar dari pada di kondisi optimal hurdle contract. Dengan demikian hipotesis 2 a diterima bahwa ada perbedaan antara kejujuran pelaporan anggaran pada tingkat penalaran moral yang rendah. Jadi, pada tingkat penalaran moral yang rendah kondisi optimal hurdle contract dapat menekan adanya kecurangan atau pembebanan biaya anggaran bahan baku secara berlebih agar individu melaporkan anggaran secara jujur tanpa mencari keuntungan pribadi sehingga laba yang diperoleh perusahaan juga dapat diperoleh secara optimal. 


\section{Hasil Pengujian Hipotesis 2b}

Pengujian pada hipotesis $2 \mathrm{~b}$ digunakan untuk mengetahui apakah terdapat perbedaan kejujuran pelaporan anggaran dengan kondisi trust contract dan optimal hurdle contract pada tingkat cognitive moral development yang tinggi.

Tabel 8. Desain Hipotesis $2 b$.

\begin{tabular}{|c|c|r|r|}
\hline \multirow{2}{*}{} & \multicolumn{2}{|c|}{ Kejujuran pelaporan anggaran } \\
\cline { 3 - 4 } & Trust contract & $\begin{array}{c}\text { Optimal hurdle } \\
\text { contract }\end{array}$ \\
\hline $\begin{array}{c}\text { Cognitive moral } \\
\text { development }\end{array}$ & Rendah & 1 & 2 \\
\cline { 2 - 4 } & Tinggi & 3 & 4 \\
\hline
\end{tabular}

Sumber: Data primer diolah, 2019

Tabel 8 diatas menyajikan desain penelitian untuk menguji hipotesis $2 \mathrm{~b}$ yang dilakukan dengan uji beda kinerja pada sel 3 dan sel 4 . Berhubung penelitian ini menggunakan independent sampel $t$ test, maka uji normalitas dilakukan terlebih dahulu untuk memastikan bahwa sampel pada penelitian ini terdistribusi normal dengan menggunakan pengujian Kolmogorov-Smirnov.

Tabel 9. Hasil Kolmogorov Smirnov Hipotesis 2b

\begin{tabular}{|c|r|r|r|r|}
\hline $\begin{array}{c}\text { Kejujuran pelaporan } \\
\text { anggaran dengan } \\
\text { tingkat Cognitive }\end{array}$ & $\begin{array}{c}\text { Asymp. } \\
\text { Sig (2- } \\
\text { tailed) }\end{array}$ & Mean & Sig. \\
\cline { 2 - 4 } $\begin{array}{c}\text { Moral Development } \\
\text { tinggi }\end{array}$ & $\begin{array}{c}\text { Kelas Trust } \\
\text { contract }\end{array}$ & 0,056 & 540.00 & 0.000 \\
\cline { 2 - 2 } & $\begin{array}{c}\text { Kelas Optimal } \\
\text { hurdle contract }\end{array}$ & & 245,45 & \\
\cline { 2 - 4 } & & &
\end{tabular}

Sumber: Data Primer diolah, 2019.

Dari Tabel 9 diatas dapat diketahui nilai p-value sebesar 0.056 untuk kondisi cognitive moral development yang tinggi pada kelas trust contract dan optimal hurdle contract. Dengan demikian hasil data terdistribusi normal dan dapat melakukan uji independent sample t test karena $p$-value lebih dari 0.05 .

Tabel 9 juga menampilkan nilai p-value sebesar 0.000 untuk pengujian perbedaan kejujuran pelaporan anggaran kelas trust contract dan optimal hurdle contract pada tingkat cognitive moral development yang tinggi. Tabel diatas menunjukan bahwa individu dengan tingkat penalaran moral yang tinggi pada kondisi trust contract memiliki rata-rata ketidak jujuran yang lebih tinggi karena membebankan biaya bahan baku lebih besar dari pada di kondisi optimal hurdle contract Dengan begitu hipotesis $2 \mathrm{~b}$ diterima bahwa terdapat perbedaan kejujuran pelaporan anggaran pada tingkat penalaran moral yang tinggi. Jadi, individu dengan moral development yang tinggi juga perlu diberikan penekanan agar melaporkan anggaran secara jujur tanpa mencari keuntungan pribadi dan agar perusahaan dapat memperoleh laba yang semestinya diperoleh.

\section{Pembahasan}

Hipotesis 1 memprediksi adanya pengaruh cognitive moral development terhadap kejujuran pelaporan anggaran. Hasil pengujian mendukung prediksi tersebut. Teori cognitive moral development mengatakan bahwa penalaran moral seseorang merupakan pertimbangan seseorang dalam pengambilan keputusan untuk melakukan sebuah tindakan. 
Tabel 10. Rata-rata pembebanan biaya

\begin{tabular}{|c|r|r|}
\hline & Trust contract & Optimal hurdle contract \\
\hline Cognitive tinggi & $\mathbf{4 8 0}$ & $\mathbf{7 0}$ \\
\hline Cognitive rendah & $\mathbf{5 0 7}$ & $\mathbf{1 3 6}$ \\
\hline
\end{tabular}

Untuk memahami lebih jaug lagi, Tabel 10 menyajikan rata-rata pembebanan biaya pada tiap kondisi dengan tingkat CMD masing-masing. Dalam kondisi trust contract partisipan lebih banyak melakukan kecurangan dengan membebankan biaya lebih besar dibandingkan pada kondisi optimal hurdle contract dan pada partisipan yang memiliki tingkat CMD yang rendah cenderung membebankan biaya lebih besar dibandingkan dengan partisipan dengan tingkat CMD yang tinggi.

Partisipan dihadapkan pada dilema etis mengenai pengambilan keputusan pada pembebanan biaya anggaran untuk bertindak secara etis dalam menyikapi adanya peluang untuk memperoleh keuntungan sendiri atau kelompok. Seseorang dengan tingkat cognitive moral development yang tinggi cenderung lebih bertindak etis dalam menyikapi hal dibandingan dengan seseorang dengan tingkat cognitive moral development yang rendah. Walaupun terdapat peluang atau kesempatan orang dengan tingkat cognitive tinggi lebih jujur dalam bertindak agar tidak merugikan pihak lain dengan mendahulukan kepentinganya atau kelompoknya untuk memperoleh keuntungan. Hasil ini konsisten dengan penelitian Chung dan Hsu (2017) bahwa cognitive moral development memberikan pengaruh seseorang melalukan tindakan untuk melaporkan anggaran secara jujur.

Hipotesis 2a memprediksi adanya perbedaan kejujuran pelaporan anggaran antara cognitive moral development tinggi dalam kondisi trust contract dan optimal hurdle contract. Sementara hipotesis $2 \mathrm{~b}$ memprediksi terdapat perbedaan kejujuran pelaporan anggaran antara cognitive moral development rendah dalam kondisi trust contract dan optimal hurdle contract. Hasil pengujian mendukung kedua hipotesis tersebut.

Hasil dalam penelitian ini menunjukan bahwa tingkat cognitive moral development yang tinggi pada kondisi trust contract lebih besar membebankan biaya anggaran daripada dalam kondisi optimal hurdle contract. Dalam tingkat cognitive moral development yang rendah pada kondisi trust contract membebankan anggaran lebih besar daripada kondisi optimal hurdle contract. Seorang dengan tingkat cognitive moral development tinggi pun ketika dihadapkan pada cela untuk melakukan kecurangan dapat bertindak secara tidak etis karena tanpa adanya pengawasan untuk memperoleh keuntungan agar dapat memperkaya diri sendiri atau kelompoknya.

Lebih jauh, hasil penelitian ini menunjukan bahwa kondisi optimal hurdle contract memberikan kontrol pada seseorang untuk bekerja secara jujur baik pada tingkat Cognitive moral development yang tinggi dan yang rendah. Seseorang dengan tingkat cognitive moral yang tinggi sekalipun dapat melakukan kecurangan dengan melaporakan biaya pembebanan anggaran secara tidak jujur sehingga kontrol seperti dalam kondisi optimal hurdle contract sangat memberikan efek pada seseorang untuk melakukan sebuah tindakan secara jujur. Hal ini dapat diartikan bahwa ketika terdapat kontrol dalam proses membebanan biaya anggaran akan membuat perilaku kejujuran lebih tinggi.

\section{SIMPULAN DAN SARAN}

\section{Simpulan}

Berikut ini kesimpulan yang diperoleh dari hasil pengujian hipotesis:

1. Hipotesis 1 yang menduga terdapat pengaruh kejujuran pelaporan anggaran pada cpgnitive moral development diterima dan menunjukkan bahwa adanya pengaruh pada cognitive moral development pada kejujuran pelaporan anggaran. 
2. Hipotesis 2a yang menduga terdapat perbedaan kejujuran pelaporan anggaran pad kondisi trust contract dan optimal hurdle contract pada cognitive moral development yang tinggi diterima dan menunjukkan bahwa ketika seseorang dengan berada pada kondisi optimal hurdle contract lebih jujur dalam melaporkan penyusunan anggaran dibandingkah pada kondisi trust contract.

3. Hipotesis $2 \mathrm{~b}$ yang menduga terdapat perbedaan kejujuran pelaporan anggaran pad kondisi trust contract dan optimal hurdle contract pada cpgnitive moral development yang rendah diterima dan menunjukkan bahwa ketika seseorang dengan berada pada kondisi optimal hurdle contract lebih jujur dalam melaporkan penyusunan anggaran dibandingkah pada kondisi trust contract.

4. Kondisi optimal hurdle contract memberikan tekanan pada seseorang untuk melaporakan secara jujur dan kondisi tersebut sangat baik juga orang orang dengan tingkat cognitive moral development yang rendah ditempatkan pada kondisi tersebut.

\section{Saran}

Penelitian selanjutnya dapat menambah variabel yang melibatkan kelompok dalam pengerjaan penyusunan anggaran untuk menambah penekanan pada kejujuran pelaporan anggarannya. Bagi Perusahaan sebaiknya menempatkan seseorang yang memiliki tingkat cognitive moral development yang rendah pada kondisi optimal hurdle contract dan untuk seseorang dengan tingkat cognitive moral development yang tinggi alangkah lebih baiknya diberikan pada kondisi optimal hurdle contract untuk mengantisipasi terjadinya penyimpangan. Dalam mencari karyawan baru sebaiknya diberikan juga test yang mengukur cognitive moral development untuk menekan kecurangan dalam perusahaan.

\section{DAFTAR PUSTAKA}

Adelin, V. 2013. Pengaruh Pengendalian Internal, Ketaatan Aturan, dan Perilaku Tidak Etis Terhadap Kecenderungan Kecurangan Akuntansi (Studi Empiris Pada BUMN di Kota Padang). September, 55-60.

Chung, J. O. Y., and Hsu, S. H. 2017. The Effect of Cognitive Moral Development on Honesty in Managerial Reporting. Journal of Business Ethics, 145(3), 563-575.

Evans, J. H. 2001. Honesty in managerial reporting. Accounting Review, 76(4), 537-559.

Hartono, J. 2013. Metodologi Penelitian Bisnis : Salah Kaprah dan Pengalaman-Pengalaman. (6th ed.). BPFE - Yogyakarta.

Iqbal, S., and Sholihin, M. 2016. Peran Perkembangan Moral Kognitif Dalam Keputusan Dilema Moral: Analisis Kepatuhan Pajak Di Dalam Iklim Synergistic dan Antagonistic. Simposium Nasional Akuntansi XIX, 1-26.

Mcmahon, J. 2000. The Effects of Cognitive Moral Development and Reinforcement Contingencies on Ethical Decision Making by. Dissertation, 1-144.

Mila, E. 2018. Pengaruh Moral Reasoning, sifat Machiavellian, dan Time Budget Pressure Terhadap Pengambilan keputusan Etis Auditor dengan Oritnetasi Etika sebagai Variabel Moderating. Diakses melalui http://repositori.uin-alauddin.ac.id/12622/1/Pengaruh moral reasoning.pdf. 
Palupi, M. dan Mulyanto, C. B. 2014. Model Moral Judgment Sebagai Penjelas Perilaku Kekenduran Anggaran.

Puspasari, N. E. S. 2012. Pengaruh Moralitas Individu Dan Pengendalian Internal Terhadap Kecenderungan Kecurang Akantansi: Studi Eksperimen Pada Konteks Pemerintah Daerah. 1-30.

Rosdini, D. 2013. Shared Financial Interest, Fairness, dan Kejujuran dalam Pelaporan Anggaran. September 2013, 25-28.

Sutrisni. 2014. Pengaruh komitmen organisasi dan gaya kepemimpinan terhadap hubungan antara partisipasi anggaran dan kinerja manjerial. diakses dari http://eprints.ums.ac.id/31906/9/02. NASKAH PUBLIKASI.pdf 